\title{
Curcumin and Glu-GNPs Induce Radiosensitivity against Breast Cancer Stem-Like Cells
}

\author{
Ke Yang $\left(\mathbb{D},{ }^{1}\right.$ Zhiwei Liao $\mathbb{D}^{2},{ }^{2}$ Yujian Wu $\left(\mathbb{D},{ }^{1}\right.$ Mengjie Li $\mathbb{D}^{1},{ }^{1}$ Tingting Guo $\mathbb{D}^{1},{ }^{1}$ Jiayi Lin $\mathbb{D}^{1},{ }^{1}$ \\ Yanwu Li $\mathbb{D}^{3},{ }^{3}$ and Chenxia $\mathrm{Hu} \mathbb{D i D}^{1}$ \\ ${ }^{1}$ School of Pharmaceutical Science, Guangzhou University of Chinese Medicine, Guangzhou 510006, China \\ ${ }^{2}$ Guangzhou Medical University Affiliated Cancer Hospital, Guangzhou 510635, China \\ ${ }^{3}$ Science and Technology Innovation Center, Guangzhou University of Chinese Medicine, Guangzhou 510006, China
}

Correspondence should be addressed to Yanwu Li; liyanwu@gzucm.edu.cn and Chenxia Hu; 20010614@gzucm.edu.cn

Ke Yang and Zhiwei Liao contributed equally to this work.

Received 7 July 2020; Revised 5 December 2020; Accepted 14 December 2020; Published 28 December 2020

Academic Editor: Vickram Ramkumar

Copyright ( $) 2020$ Ke Yang et al. This is an open access article distributed under the Creative Commons Attribution License, which permits unrestricted use, distribution, and reproduction in any medium, provided the original work is properly cited.

\begin{abstract}
Breast cancer stem cells are an important cause of radiotherapy resistance in the clinical treatment of breast cancer patients. How to target breast cancer stem cells is the key to improving the efficacy of breast cancer radiotherapy. We proposed for the first time that curcumin combined with glucose nanogold particles (Glu-GNPs) targeted breast cancer stem cells to reduce radiotherapy resistance, which can significantly enhance the apoptosis level of MCF-7 and MDA-MB-231 breast cancer stem-like cells (BCSCs) after radiotherapy and antiproliferation and colony-forming. Under simulated hypoxic conditions, curcumin combined with Glu-GNPs can significantly improve the ROS level of MCF-7 and MDA-MB-231 mammospheres; reduce the expression of HIF- $1 \alpha$ and HSP90, thereby inhibiting the tumor cells' own stress ability; promote the apoptosis of tumor stem cells; and enhance the sensitivity of radiotherapy. The current results indicate that the combination of curcumin and Glu-GNPs has great potential to relieve tumor hypoxia and increase radiosensitivity on BCSCs, providing scientific research data for developing a novel radiosensitizer with high efficiency and low toxicity.
\end{abstract}

\section{Introduction}

Breast carcinoma is the most prevalent female malignancy and has high mortality rate, only next to lung cancer. Rebecca et al. [1] predicted the number of new cases of infiltrating carcinoma in America in 2019. There will be nearly 268,600 new cases of breast malignancy accounting for $30 \%$ of all new cancer diagnoses, and 41,760 deaths are from breast cancer accounting for $15 \%$ of all cancer deaths in women.

Although the currently available treatments may eliminate the primary tumor, many patients still die from tumor relapse and metastasis. Accumulating evidence indicates that a minor population of special cells in cancer tissue, which are similar to normal stem cells, acts as an important part to tumor formation and growth. Their characteristics of selfrenewal, strong proliferation capacity, multidifferentiation potential, and strong oncogenicity indicate that they may be the source of tumorigenesis, relapse, and metastasis of cancer. Radiation therapy is one of the conventional methods to treat breast cancer and has showed great efficacy in clinical practice. However, breast cancer recurrence and metastasis after radiotherapy and the development of radioresistance after repeated irradiations represent a major challenge.

In 2003, Al-Hajj et al. [2] firstly isolated stem cell-specific surface marker $\mathrm{CD} 44^{+} \mathrm{CD} 24^{- \text {llow }}$ cells from breast tumor tissue. Many studies have indicated that BCSCs exhibit stronger resistance to radiotherapy and chemotherapy compared with ordinary breast cancer cells [3-6]. Phillips et al. [7] used the clone formation test to detect cell survival fractions at $2 \mathrm{~Gy}$ irradiation (SF2); it was observed that SF2 was higher in MCF-7 and MDA-MB-231 stem cells (0.46 and 0.69, respectively) compared to their respective adherent cells (0.2 and 
0.5 , respectively). The levels of $\gamma \mathrm{H} 2 \mathrm{AX}$ and ROS suggested that the microsphere stem cells were less prone to DNA damage. It was the first time that BCSCs were confirmed to have strong radiotherapy resistance characteristics. In view of the radiotherapy resistance leading to cancer relapse and metastasis, new treatment methods targeting cancer stem cells are crucial for inhibiting the development of breast cancer.

Gold nanoparticles (GNPs) are a type of nanomaterial approved for clinical trials by FDA in the US. It was demonstrated that, when nanometal particles were irradiated by Xray, the effect of ionizing radiation on the tumor cells was enhanced, which promoted the release of free radicals, damaging DNA and inducing cell apoptosis [8-11]. Our previous study showed that Glu-GNPs were assimilated in MCF-7 adherent cells and THP-1 suspension cells more easily than GNPs [12] It suggested that glucose tagging may be a right way for promoting the uptake of GNPs in tumor cells, as tumor cells can take up more glucose than normal cells. In addition, it was previously demonstrated that these nanometal particles enhanced killing effects on tumor cells without increasing damage to the surrounding normal tissues in a mouse model, thereby reducing the adverse effects of radiotherapy $[13,14]$.

Curcumin is an active compound extracted from the underground rhizome of the tumeric plant. It has widespread function in preventing and treating tumor. There are some accumulating evidences indicating that curcumin can enhance the radiosensitivity in several types of cancer [1517]. Our studies have demonstrated that curcumin inhibited mammosphere formation, characteristics of stem cells in BCSCs [18]. We herein aimed to investigate whether curcumin and Glu-GNPs can enhance the radiosensitivity in BCSCs and the underlying mechanism.

In our study, we confirmed the inhibiting effects on cell proliferation and clone formation of curcumin and GluGNPs, alone and in combination, in both types of spheres after X-ray irradiation. The radiosensitivity was further enhanced by treatment with curcumin combined with GluGNPs. Under hypoxic conditions, the curcumin group, the Glu-GNP group, and the combination group all showed G0/G1 cell cycle arrest. Induction of apoptosis and increased ROS levels were observed in spheres either irradiated with Xray alone or treated with a combined application of curcumin, Glu-GNPs, and X-ray. Furthermore, curcumin and Glu-GNPs downregulated the HIF- $1 \alpha$ and HSP90 expression in both types of tumor spheres.

\section{Materials and Methods}

2.1. Compound and Chemicals. Curcumin (purity $\geq 77 \%$ ), thiopolyethylene glycol (thio-PEG), and 1-thio-d-glucose (Glu) were bought from Sigma-Aldrich, Germany. $\mathrm{CoCl}_{2}$ was purchased from AMRESCO (Cleveland, OH, USA).

2.2. Adherent Cell and Tumor Sphere Culture. MCF-7 and MDA-MB-231 cells were obtained from ATCC (Manassas, VA, USA). They were cultivated in Dulbecco's modified Eagle's medium (DMEM) containing 10\% FBS and 1\% P/S (Gibco, USA) in an incubator with $5 \% \mathrm{CO}_{2}$ at $37^{\circ} \mathrm{C}$. Then, according to the culture method reported by Dontu et al. $[19,20]$, the two kinds of breast cancer cells were plated in ultralow attachment 6-well plates with SFM including DMEM-F12 (Gibco), P/S, bFGF, EGF, B27 (Cyagen, USA), insulin, and BSA (Sigma-Aldrich). The growth medium was replenished every 2 days with fresh medium. Cells cultured under the condition forming nonattached tumor spheres were digested once a week. Third-generation spheres were collected to detect the $\mathrm{CD} 44^{+} \mathrm{CD} 24^{- \text {/low }}$ cells by FCM (BD Accuri $^{\mathrm{TM}}$ C5, USA).

2.3. Synthesis of Glu-GNPs and Cell Uptake. Referring to our previously described method [12], the complex of thio-PEG and glucose was added to the solution of GNPs (Beijing DK Nanotechnology Co., Ltd., Beijing, China) and well-mixed to obtain the final solution of Glu-GNPs. The sample was performed by centrifugation for $30 \mathrm{~min}\left(9000 \mathrm{~g}, 4^{\circ} \mathrm{C}\right)$ to remove supernatant. The cell uptake of GNPs and GluGNPs was examined using transmission electron microscopy (TEM). MDA-MB-231 spheres $\left(1 \times 10^{6} /\right.$ per well $)$ were seeded in ultralow attachment 6 -well plates for $24 \mathrm{~h}$. The cells were starved for $6 \mathrm{~h}$ by changing the medium without serum. The drug groups were treated with $0.1 \%$ GNPs or Glu-GNPs $(20 \mu \mathrm{L}$ per $1 \mathrm{~mL}$ medium) for $6 \mathrm{~h}$, and the controls were treated with deionized water. The spheres were fixed by 2.5\% glutaraldehyde, dehydrated, and paraffin embedded, and ultrathin sections were cut and examined by TEM.

2.4. Cell Treatment. Single-cell suspensions obtained from MCF-7 and MDA-MB-231 spheres were inoculated at $4 \times$ $10^{5}$ per well in 6-well plates. After treatment with $30 \mu \mathrm{M}$ curcumin for $24 \mathrm{~h}$, cells were starved in the medium without serum for $6 \mathrm{~h}$. DMSO was used as a control. The cells were then treated with $0.1 \%$ Glu-GNPs $(20 \mu \mathrm{L}$ per $1 \mathrm{~mL}$ medium). After $6 \mathrm{~h}$, the cells were washed with PBS and then supplemented with fresh medium containing serum.

2.5. Irradiation. Irradiation was performed with a $6 \mathrm{MV} \mathrm{X}$ ray at a total dose of 0 and $4 \mathrm{~Gy}$ using the two-photon medical linear accelerator Elekta Synergy 3630 (Elekta Instrument $A B$, Stockholm, Sweden). The dose rate was $2 \mathrm{~Gy} / \mathrm{min}$, with radiation for two minutes. The depth of the treatment was $2 \mathrm{~cm}$, and the irradiation distance is $50 \mathrm{~cm}$.

2.6. Cell Viability and Clone Formation Test. After they were irradiated by X-ray, cell suspensions of the two types of spheres were separately inoculated $\left(2.5 \times 10^{4}\right.$ per well $)$ in 96-well plates and incubated. Afterwards, $10 \mu \mathrm{L} \mathrm{CCK-8} \mathrm{solu-}$ tion (EnoGeneCell Counting Kit-8; EnoGene Biotech Co., NY, USA) was added to each well and incubated for $3 \mathrm{~h}$. The absorbance of each well was measured using a PerkinElmer EnSpire Reader at $490 \mathrm{~nm}$ (Perkin Elmer, Waltham, MA, USA). The cell viability of the treated cells was expressed relative to that of the cells treated with DMSO only. All values are presented as the mean \pm standard deviation of at least triplicate samples. Meanwhile, the spheres were suspended in DMEM containing serum and inoculated in 6-well plates (500 cells per well). All the cells were cultured in the medium for $14 \mathrm{~d}$. The colonies were fixed with paraformaldehyde, then stained with Giemsa for $30 \mathrm{~min}$. The clones were 
observed and counted. The experiment was repeated 3 times, and the average was taken.

2.7. Hypoxic Treatment. Chemical hypoxia was induced with $100 \mu \mathrm{mol} / \mathrm{mL} \mathrm{CoCl}_{2}$ on the two types of spheres for $2 \mathrm{~h}$ prior to X-ray. Under hypoxic conditions, cell cycle distribution, apoptosis rates, and ROS levels in each group were detected by FCM using BD Accuri ${ }^{\mathrm{TM}} \mathrm{C} 5$ (BD Biosciences).

2.8. Cell Apoptosis Detection. Apoptotic rate was assessed referring to the protocol of the double-staining cell apoptosis kit (BestBio, China). After $12 \mathrm{~h}$ of irradiation under hypoxic conditions, the spheres were digested and washed with PBS, centrifuged, and suspended in a $500 \mu \mathrm{L}$ binding buffer $\left(1 \times 10^{6} \mathrm{cells} / \mathrm{mL}\right)$. The spheres were stained with AnnexinV-FITC $(50 \mu \mathrm{g} / \mathrm{mL}, 5 \mu \mathrm{L})$ followed by the addition of PI $(50 \mu \mathrm{g} / \mathrm{mL}, 10 \mu \mathrm{L})$. The samples were analyzed by FCM.

2.9. Cell Cycle Detection. After $12 \mathrm{~h}$ of irradiation under hypoxic conditions, the mammospheres were collected and digested into a single-cell suspension with $0.05 \%$ trypsin and washed twice with PBS, then centrifuged for $5 \mathrm{~min}$ at $800 \mathrm{~g}$, and suspended in $500 \mu \mathrm{L}$ cold PBS and fixed with $70 \%$ ethanol at $4^{\circ} \mathrm{C}$ for $12 \mathrm{~h}$. The cells $\left(1 \times 10^{6}\right.$ cells $\left./ \mathrm{mL}\right)$ were treated with RNase solution $(80 \mathrm{mg} / \mathrm{mL}, 20 \mu \mathrm{L})$ and propidium iodide $(50 \mu \mathrm{g} / \mathrm{mL}, 400 \mu \mathrm{L})$ for $1 \mathrm{~h}$. The stained cells were assessed by FCM.

2.10. ROS Level Analysis. ROS levels in the irradiated cells were detected with a ROS assay kit (Thermo Fisher Scientific). After irradiation, the spheres were cultured with a new medium for $12 \mathrm{~h}$, digested, and centrifuged. Cells were washed with PBS and suspended in a $400 \mu \mathrm{L}$ ROS assay buffer. Cell suspension $\left(1 \times 10^{6}\right.$ cells $\left./ \mathrm{mL}\right)$ was treated with 1x ROS Assay Stain while avoiding light to incubate for $1 \mathrm{~h}$ at $37^{\circ} \mathrm{C}$ and then analyzed by FCM.

2.11. mRNA Expression Analysis. Total RNA was extracted by using a TRIGene kit (GenStar Biosolutions, China), and cDNA was synthesized from $1 \mathrm{mg}$ of total RNA according to the protocol. The primer sequences are shown in Table 1. The quantitative PCR kit (Takara Biomedical Technology Co., China) was used for real-time PCR analysis.

2.12. Protein Expression Analysis. Total proteins from the MCF-7 and the MDA-MB-231 sphere were extracted and measured, and the BCA protein quantitative kit (Beyotime, China) was used to quantify the protein concentration. Rabbit anti-human HIF-1 $\alpha$ (Abcam, ab243860) and rabbit antihuman HSP90 (Cell Signaling Technology, \#4877) monoclonal antibodies $(1: 1,000)$ were used for incubation overnight at $4^{\circ} \mathrm{C}$. Secondary antibodies $(1: 2,000)$ for $1 \mathrm{~h}$ at room temperature. Western blot images were detected with a Tanon 5200 Multi Chemiluminescent Imaging system (Tanon Science and Technology, China), and ImageJ software (National Institutes of Health, Bethesda, MD, USA) was used to analyze the gray values of each group.

2.13. Statistical Analysis. Statistical analyses were performed using an Anova test (one way or two way depending upon
TABLE 1: Reverse transcription-quantitative polymerase chain reaction.

\begin{tabular}{lc}
\hline Genes & Primers $\left(5^{\prime}-3^{\prime}\right)$ \\
\hline \multirow{2}{*}{-Actin } & F: CTCCATCCTGGCCTCGCTGT \\
& R: GCTGTCACCTTCACCGTTCC \\
HIF-1 $\alpha$ & F: ACGTTCCTTCGATCAGTTGTCACC \\
& R: GGCAGTGGTAGTGGTGGCATTAG \\
HSP90 & F: CCAGTTCGGTGTTGGTTTTTAT \\
& R: CAGTTTGGTCTTCTTTCAGGTG \\
\hline
\end{tabular}

the type of data) in GraphPad software. The results were presented as the mean \pm standard deviation of triplicate experiments, and $P<0.05$ was considered to indicate a statistically significant difference.

\section{Results}

3.1. $\mathrm{CD}_{4} 4^{+} \mathrm{CD} 24^{-}$Cells Were Increased in Tumor Mammospheres. MCF-7 and MDA-MB-231 adherent cells were cultured with SFM, and the third-generation spheres were harvested (Figure 1(a) and 1(b)). As CD $44^{+} \mathrm{CD} 24^{-/ \text {low }}$ is a key marker of BCSCs, the $\mathrm{CD} 44^{+} \mathrm{CD} 24^{-}$subpopulation in the two types of adherent cells and spheres was detected by FCM. The proportion of $\mathrm{CD} 44^{+} \mathrm{CD} 24^{-}$cells was significantly increased in MCF-7 spheres $(66.75 \pm 0.05 \%)$ compared with MCF-7 adherent cells $(29.7 \pm 0.12 \%), P<0.01$; in addition, the biomarker of MDA-MB-231 spheres increased from $94.50 \pm 0.02 \%$ to $98.35 \pm 0.01 \%(P<0.05)$ (Figure 1(c)).

3.2. Cellular Uptake of Glu-GNPs in Mammospheres. After TEM observation, it was found that both GNPs and GluGNPs were absorbed by MDA-MB-231 spheres, especially Glu-GNPs which had more uptake than GNPs, as seen in Figure 1(d) and 1(e). The uptake distribution of MCF-7 cells for GNPs and Glu-GNPs has been published [12].

3.3. Effects of Curcumin Combined with Glu-GNPs on Cell Viability in Mammospheres. Curcumin and Glu-GNPs, alone and in combination, exerted inhibition on the two types of spheres after $4 \mathrm{~Gy}$ irradiation $(P<0.05)$. The radiosensitivity was further enhanced by treatment with curcumin combined with Glu-GNPs $(P<0.01)$. With 0 Gy irradiation, curcumin alone and curcumin combined with Glu-GNPs decreased viability on both kinds of spheres $(P<0.05)$, and there is no statistical difference between curcumin alone and curcumin combined with Glu-GNPs, $P>0.05$ (Figure 2(a) and 2(b)). Curcumin itself was effective in inhibiting viability of spheres, and its combination with Glu-GNPs enhanced the effectiveness of radiotherapy.

3.4. Clone Formation Ability Was Repressed by Curcumin Combined with Glu-GNPs. Without irradiation, the curcumin group and the curcumin in combination with GluGNP group exerted antiproliferation on the two types of spheres. After irradiation with $4 \mathrm{~Gy}$, curcumin and GluGNPs, alone and in combination, inhibited the clone- 


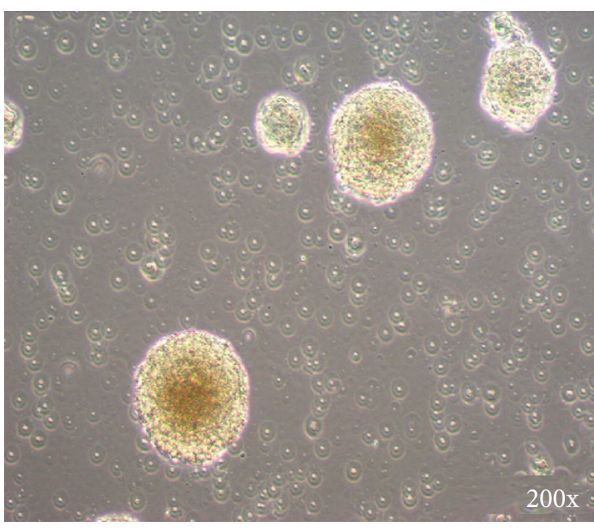

(a)

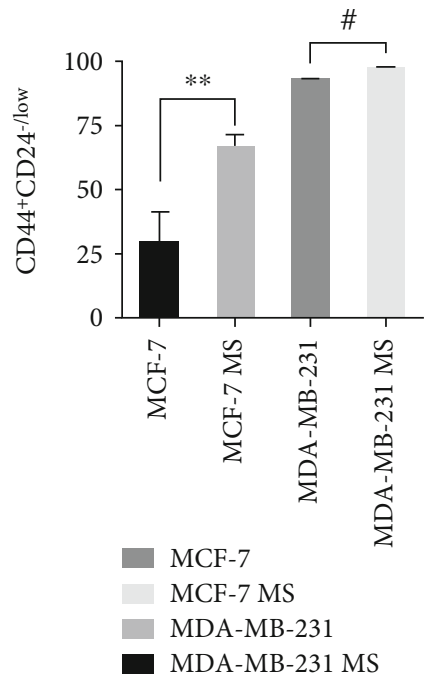

(c)

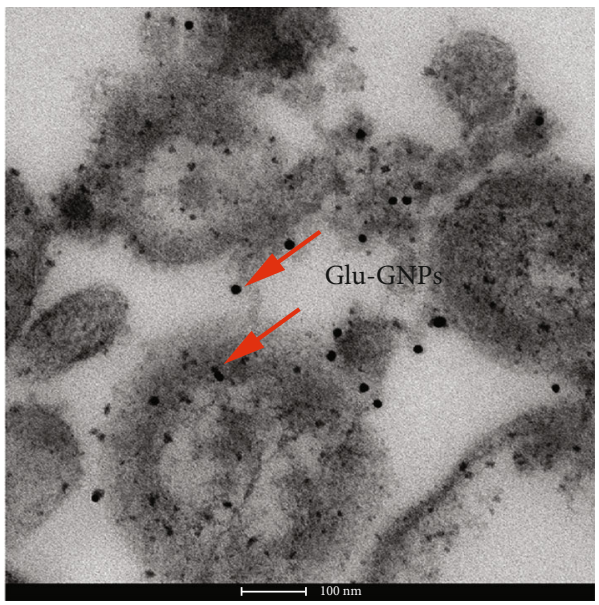

(e)

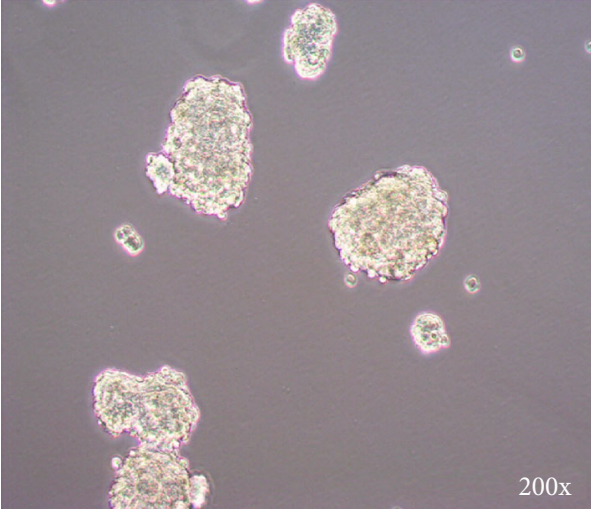

(b)

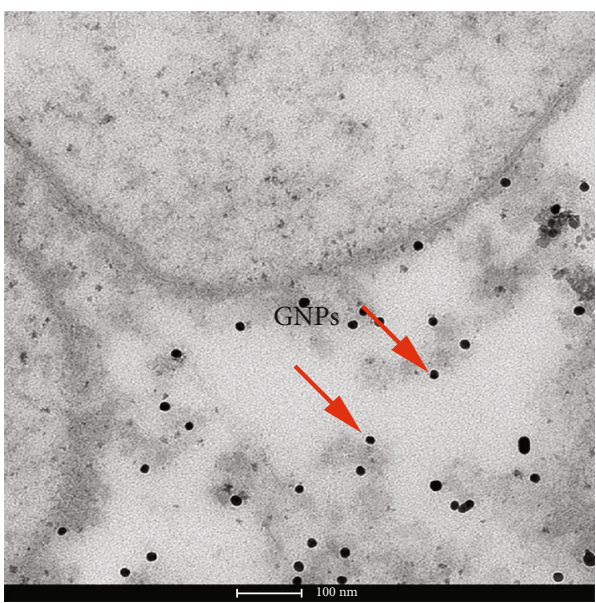

(d)

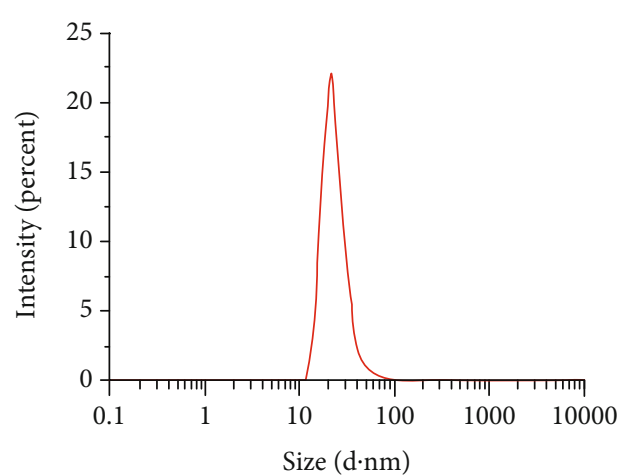

(f)

Figure 1: Cell morphology and cell intake of GNPs, Glu-GNPs in MDA-MB-231 MS by TEM: (a) MCF-7 MS; (b) MDA-MB-231 MS; (c) $\mathrm{CD} 44^{+} \mathrm{CD} 24^{- \text {llow }}$ cells were increased in two types of spheres; (d) GNPs; (e) Glu-GNPs; (f) size for the Glu-GNPs measured by NanoSight. ${ }^{* *} P<0.01$ and ${ }^{\#} P<0.05$. TEM: transmission electron microscopy; GNPs: gold nanoparticles; Glu-GNPs: GNPs with glucose; MS: mammospheres.

forming ability in the two kinds of spheres $(P<0.05)$. Curcumin showed inhibition of colony formation in MDA-MB231 spheres significantly after $4 \mathrm{~Gy}$ irradiation $(P<0.01)$.
The radiosensitivity was further enhanced by treatment with curcumin combined with Glu-GNPs in both types of spheres $(P<0.01$; Figure 2(c) and 2(d)). 

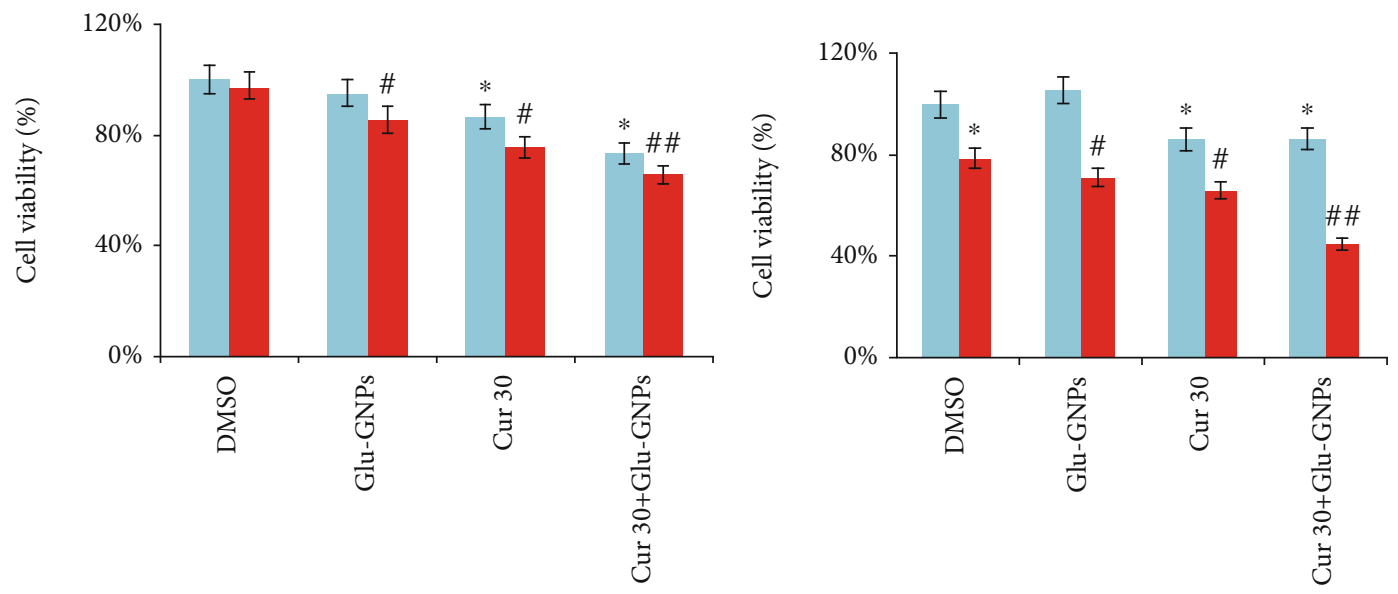

$$
\begin{aligned}
& 0 \mathrm{~Gy} \\
& \text { - } 4 \mathrm{~Gy}
\end{aligned}
$$

$$
\begin{aligned}
& \text { - } 0 \mathrm{~Gy} \\
& \text { - } 4 \mathrm{~Gy}
\end{aligned}
$$

(a)

(b)
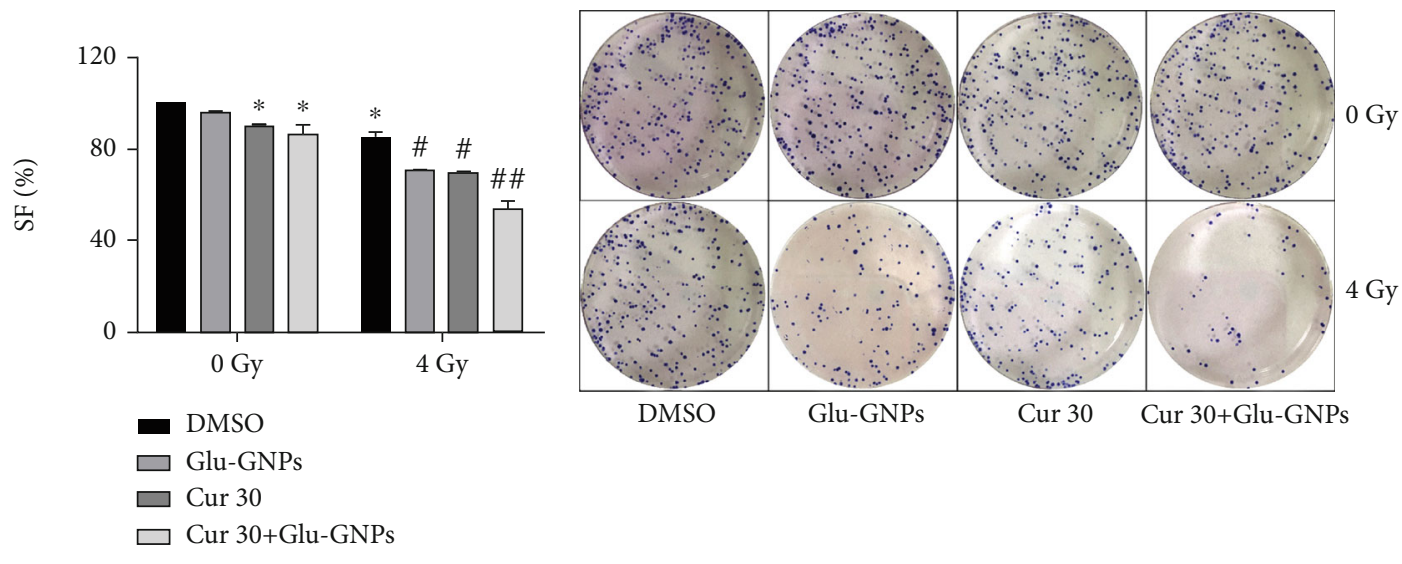

(c)
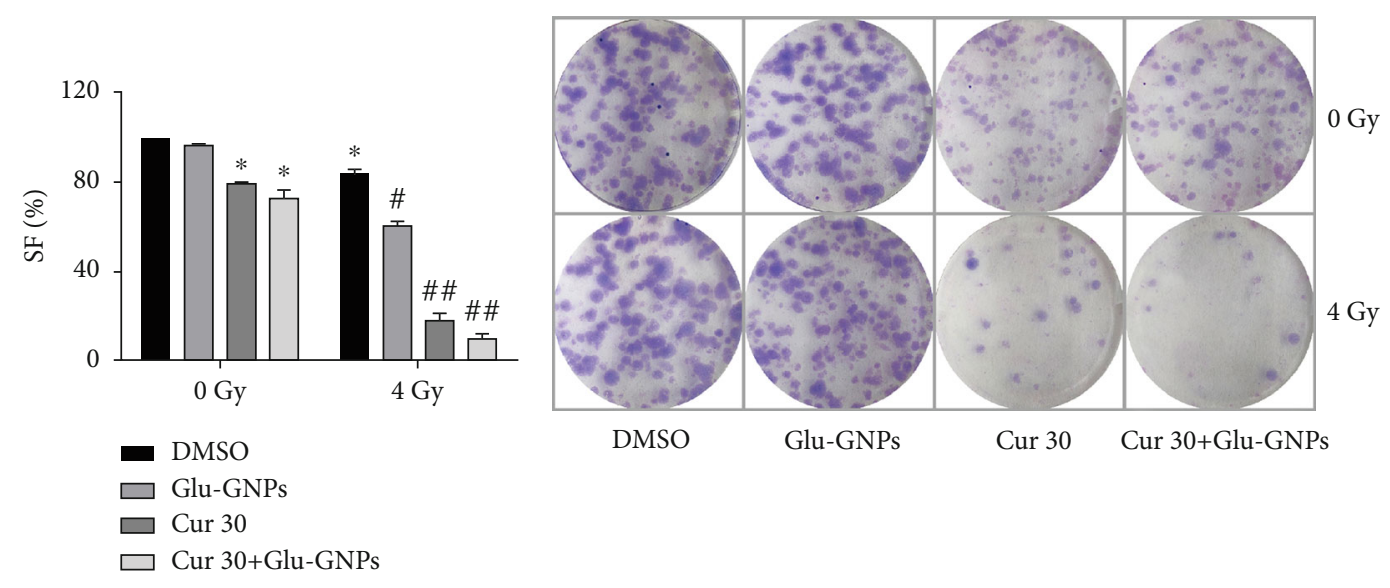

(d)

FIgURE 2: Cell viability and clone-forming capability was suppressed by curcumin and Glu-GNPs with 0 or 4 Gy radiotherapy. Viability was measured in (a) MCF-7 MS and (b) MDA-MB-231 MS. Survival fraction (SF) and colonies of (c) MCF-7 MS and (d) MDA-MB-231 MS. The data were normalized to the control. ${ }^{*} P<0.05$ vs. control at $0 \mathrm{~Gy} ;{ }^{\#} P<0.05$ and ${ }^{\# \#} P<0.01$ vs. control at $4 \mathrm{~Gy}$.

3.5. Effects of Curcumin and Glu-GNPs on Spheres under Hypoxic Condition. The apoptosis of cells was further enhanced by treatment with curcumin combined with Glu-
GNPs $(P<0.01)$. The apoptosis level was increased by curcumin and curcumin with Glu-GNPs after 0 Gy in both MCF-7 and MDA-MB-231 mammospheres $(P<0.05$; 


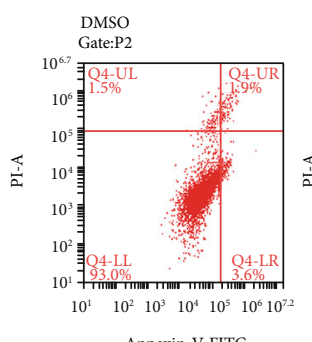

Annexin-V-FITC

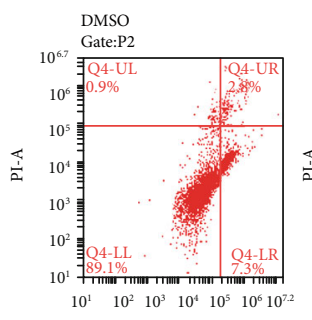

Annexin-V-FITC

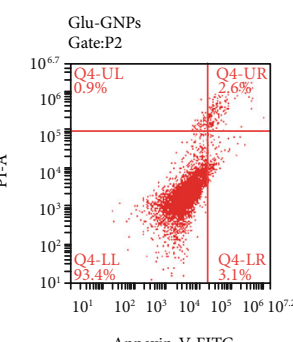

Annexin-V-FITC

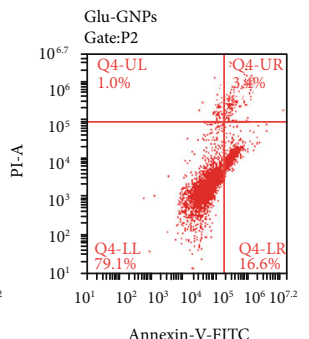

Annexin-V-FITC

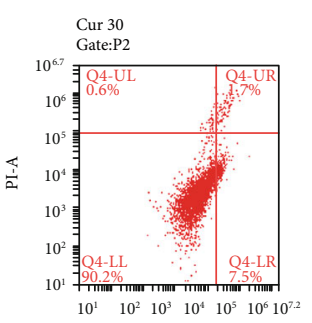

Annexin-V-FITC

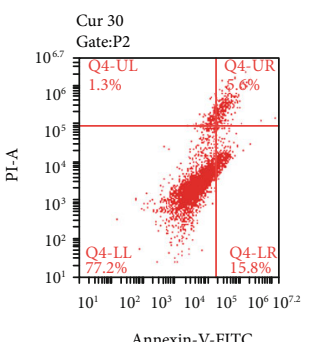

Annexin-V-FITC

(a)

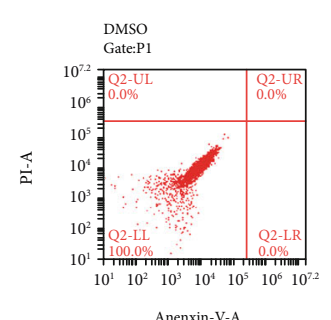

Anenxin-V-A

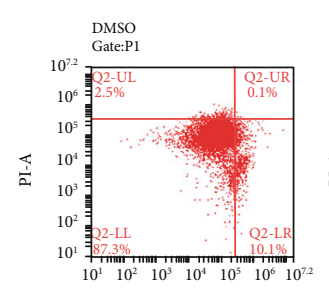

Anenxin-V-A

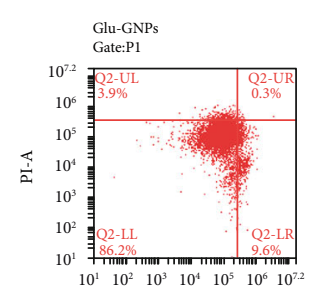

Anenxin-V-A

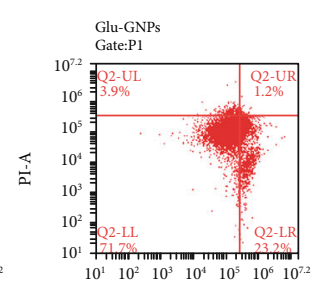

Anenxin-V-A

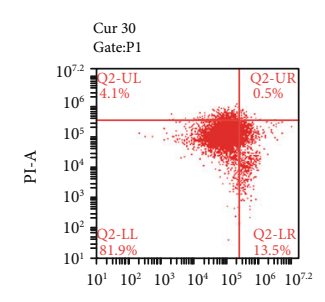

Anenxin-V-A

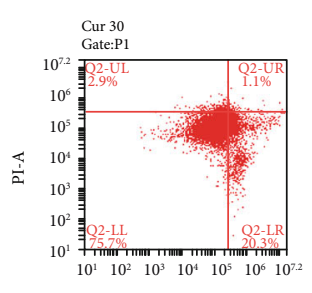

Anenxin-V-A

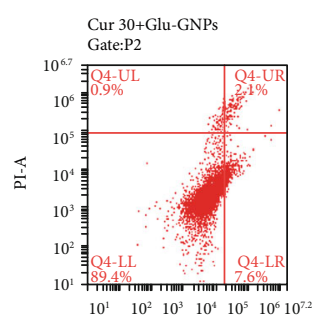

Annexin-V-FITC

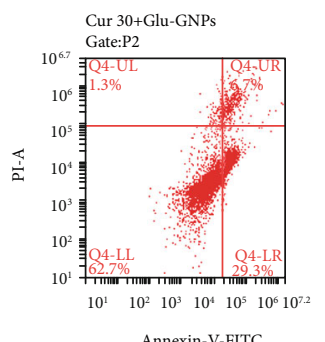

Annexin-V-FITC

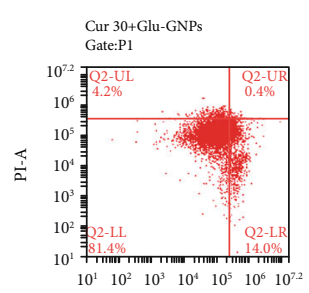

Anenxin-V-A

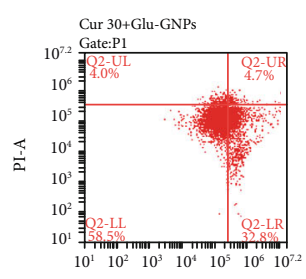

Anenxin-V-A

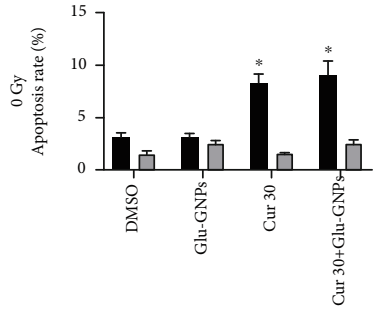

- Early apoptosis
口 Late apoptosis

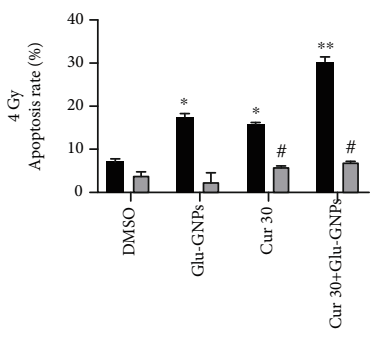

- Early apoptosis

$\square$ Late apoptosis

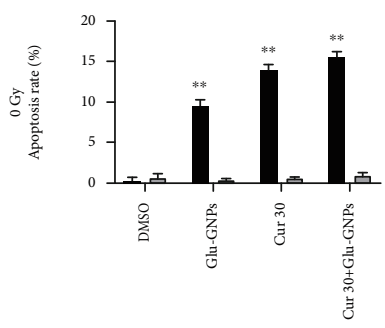

Early apoptosis
Late apoptosis

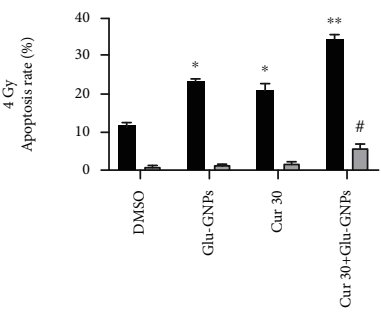

Early apoptosis

(b)

FIGURE 3: Curcumin and Glu-GNPs with radiotherapy promoted apoptosis rate of breast cancer spheres. The apoptotic rates were detected by FCM in (a) MCF-7 MS and (b) MDA-MB-231 MS. ${ }^{*} P<0.05$ vs. DMSO group at early apoptosis; ${ }^{\#} P<0.05$ and ${ }^{\# \#} P<0.01$ vs. DMSO group at late apoptosis.

Figure 3). MCF-7 and MDA-MB-231 mammospheres were irradiated after $\mathrm{CoCl}_{2}$ treatment $(100 \mu \mathrm{mol} / \mathrm{mL})$. The results demonstrated that the apoptosis level and G0/G1 phase cells were increased in the curcumin group and the curcumin in combination with Glu-GNP group in the two types of spheres without irradiation (Figure 4). After $4 \mathrm{~Gy}$ irradiation, curcumin and Glu-GNPs, alone and in combination, promoted cell apoptosis and G0/G1 phase arrest in both kinds of spheres. The apoptosis of cells and the number of G0/G1 phase cells were further enhanced by treatment with curcumin combined with Glu-GNPs (Figure 4(a) and 4(b)). Mean- while, ROS levels in each group increased after irradiation especially in the curcumin combined with Glu-GNP group $(P<0.01$; Figure 4(c) and 4(d)).

3.6. HIF-1 $\alpha$ and HSP90 mRNA Expression Are Affected by Curcumin and Glu-GNPs. We were surprised to find a notable increment of the HSP90 mRNA level in the two kinds of spheres of the DMSO group after $4 \mathrm{~Gy}$ irradiation $(P<0.01)$. It was estimated that HSP90 is a kind of stress protein which will produce greatly when the cancer cells are stimulated by hypoxia and radiation or other physical 


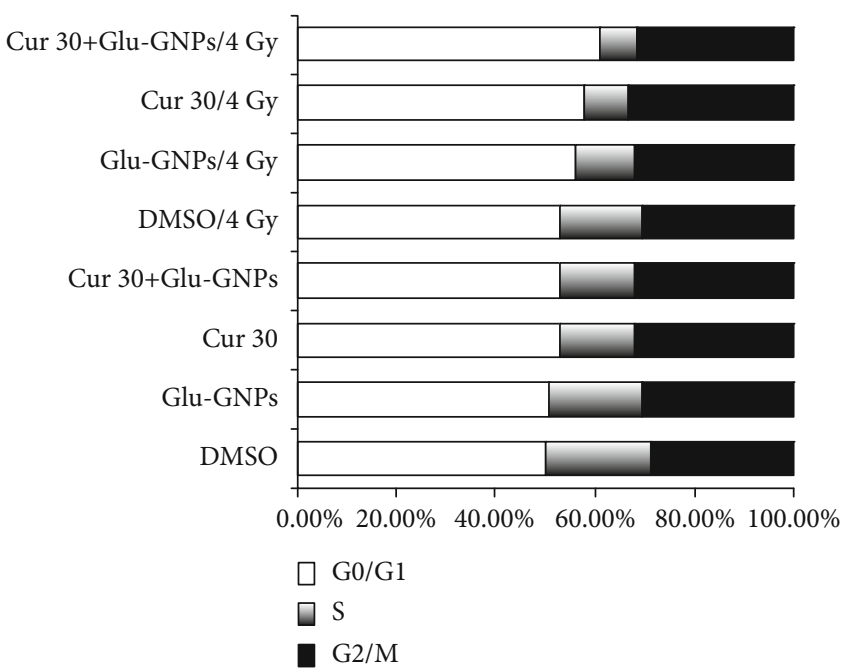

(a)

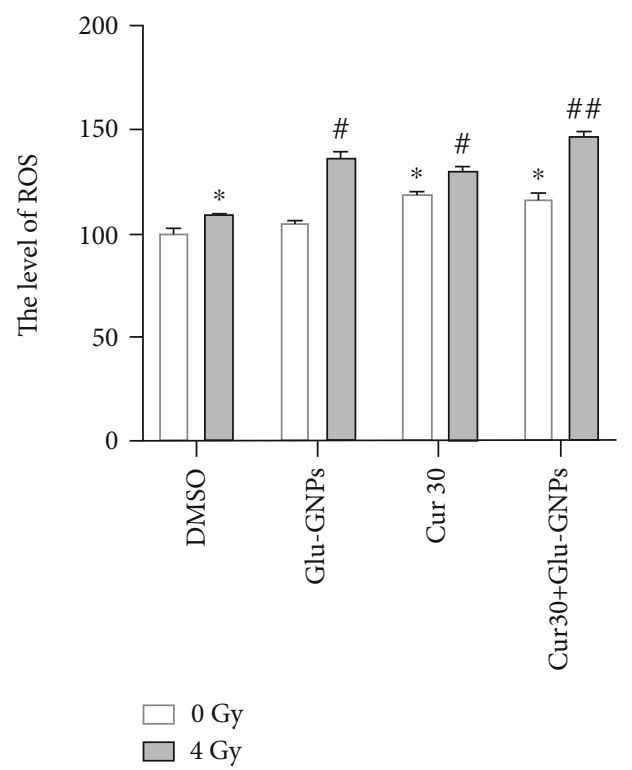

(c)

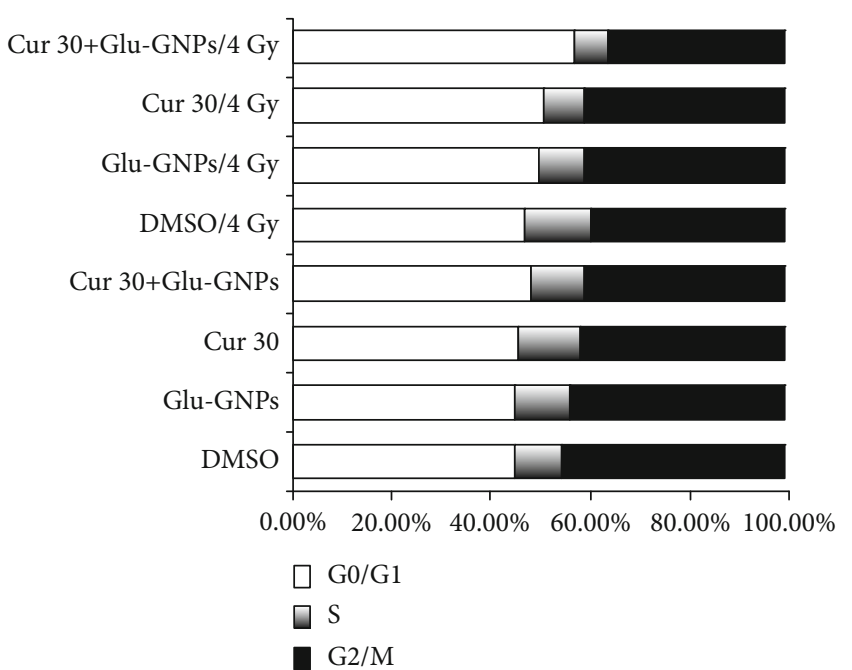

(b)

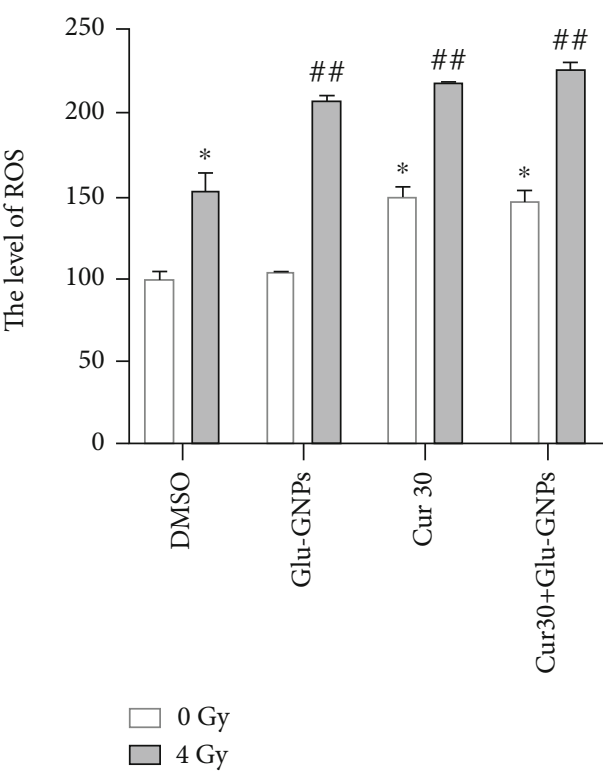

(d)

FIGURE 4: Cell cycle distribution and ROS levels were altered by curcumin and Glu-GNPs with radiotherapy in two types of spheres by FCM. The cell cycle distribution was detected in (a) MCF-7 MS and (b) MDA-MB-231 MS; detection of ROS levels in (c) MCF-7 MS and (d) MDAMB-231 MS. The data were normalized to the control. ${ }^{*} P<0.05$ indicates significance compared to the control (DMSO-treated group) with 0 Gy radiation treatment; ${ }^{\#} P<0.05$ indicates significance compared to the control (DMSO-treated group) with 4 Gy radiation treatment. ROS: reactive oxygen species.

and chemical factors to protect themselves. Curcumin alone or curcumin combined with Glu-GNPs effectively reduced the increase of HIF- $1 \alpha$ and HSP90 mRNA level caused by hypoxia or radiation in the two types of spheres $(P<0.05$, Figure 5).

3.7. Protein Level of HIF-1 $\alpha$ and HSP90 Are Affected by Curcumin and Glu-GNPs. Without irradiation, curcumin and curcumin combined with Glu-GNPs increased HIF- $1 \alpha$ and HSP90 protein levels in both types of spheres $(P<0.05$ ). However, after $4 \mathrm{~Gy}$ irradiation, both curcumin and GluGNPs decreased the HIF- $1 \alpha$ and HSP90 protein production in both kinds of spheres, respectively $(P<0.05)$. The HIF-
$1 \alpha$ and HSP90 protein expression in the cells decreased further by treatment with curcumin combined with Glu-GNPs $(P<0.01$; Figure 6).

\section{Discussion}

Curcumin is widely used as a food seasoning in some Asian countries. A great number of studies have investigated its chemopreventive activities or anticancer function on several types of cancer [21-24]. In our previous studies, we found that curcumin reduced the invasion and migration of MDA-MB-231 adherent cells as well as tumor sphere formation, stemness, and EMT process in BCSCs. In recent years, it 

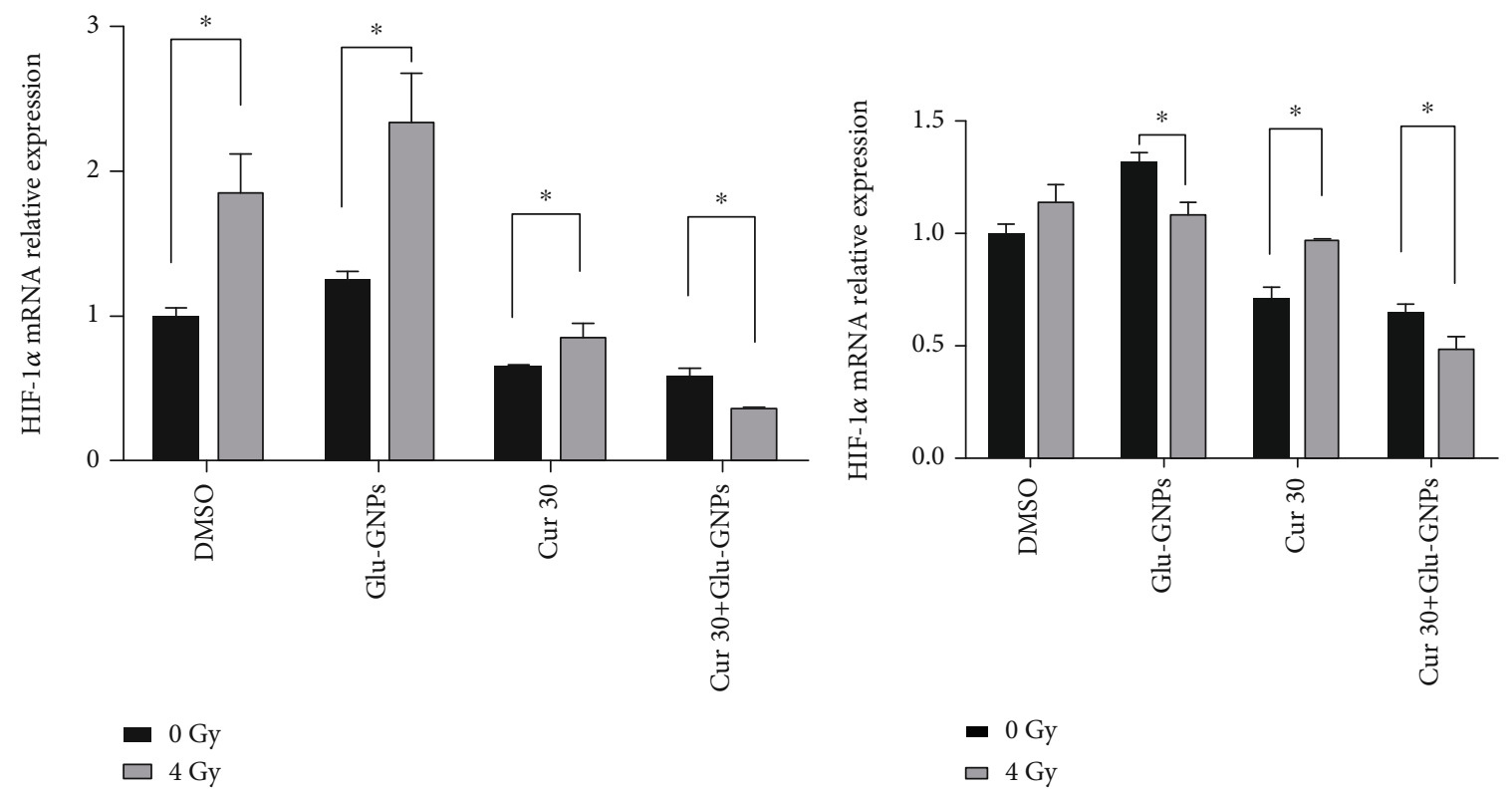

(a)

(b)

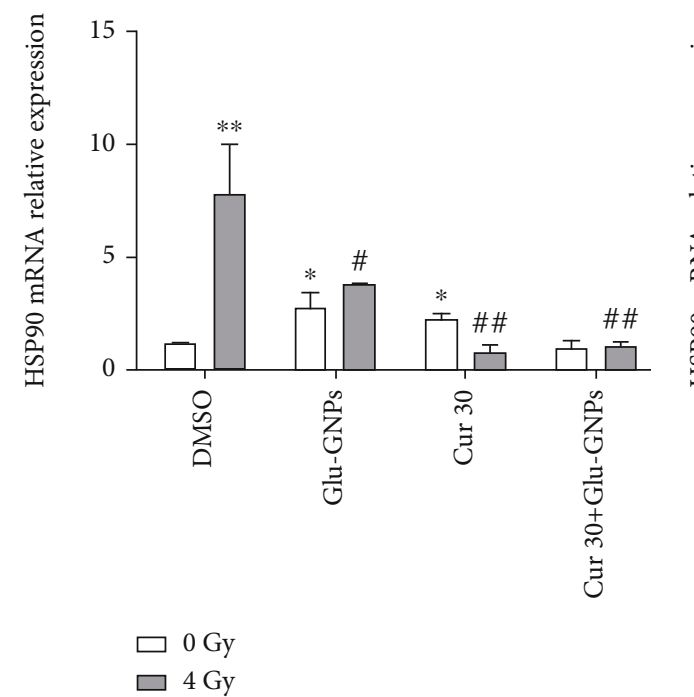

(c)

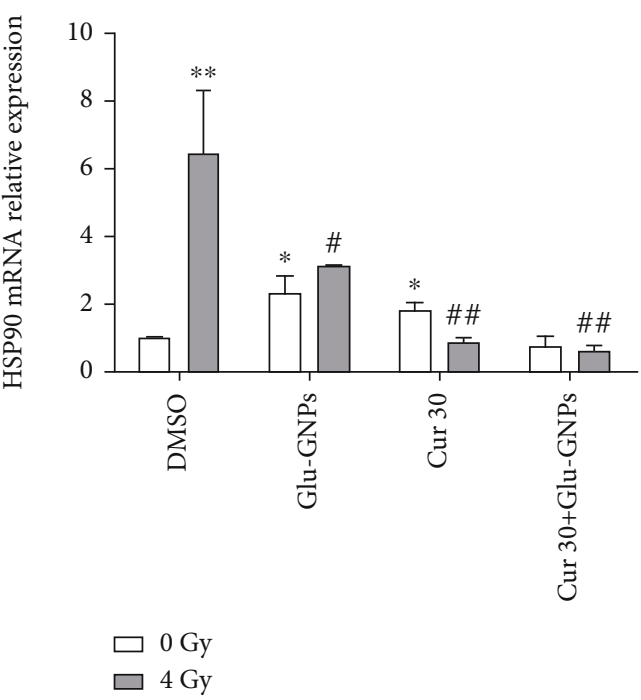

(d)

FIgURE 5: HIF- $1 \alpha$ and HSP90 mRNA expression in breast cancer spheres was regulated by curcumin and Glu-GNPs with radiotherapy. mRNA level of HIF- $1 \alpha$ in (a) MCF-7 MS and (b) MDA-MB-231 MS; mRNA level of HSP90 genes in (c) MCF-7 MS and (d) MDA-MB231 MS. $\beta$-Actin was used as the reference gene. ${ }^{*} P<0.05$ indicates significance compared to the control (DMSO-treated group) with 0 Gy radiation treatment; ${ }^{\#} P<0.05$ indicates significance compared to the control (DMSO-treated group) with 4 Gy radiation treatment.

was investigated that curcumin has a potential to enhance the effect of radiotherapy in breast cancer [25-27]. However, whether curcumin has radiosensitizing effects on BCSCs and the underlying mechanism remain unclear. In addition, our studies have demonstrated that GNPs may be a promising radiosensitizer which exerts a radiosensitizing effect on MCF-7 adherent cells and THP-1 suspension cells. Therefore, it is critical to continue to determine if curcumin could enhance the radiosensitivity of GNPs in BCSCs and to uncover the mechanisms of its radiosensitizing effect.

We selected two kinds of breast cancer cells of different differentiating degree, MCF-7 and MDA-MB-231. Tumor spheres were cultured by the suspension method, and the
$\mathrm{CD} 44^{+} \mathrm{CD} 24^{-/ \text {low }}$ subpopulation, which is recognized as a special stem-like phenotype of breast cancer, was significantly increased in spheres, which was consistent with our previous findings [18]. In the study, we found that curcumin and Glu-GNPs, alone and in combination, exerted antiproliferation and clone-forming inhibition on both types of spheres after X-ray irradiation. Curcumin combined with Glu-GNPs significantly improved the sensitivity to radiotherapy in spheres, suggesting that curcumin and GluGNPs exert a synergistic sensitizing effect.

As an unstable molecule, ROS can cause DNA damage and activate oncogenes to promote cancer which is generally considered as one of the main reasons in the development of 


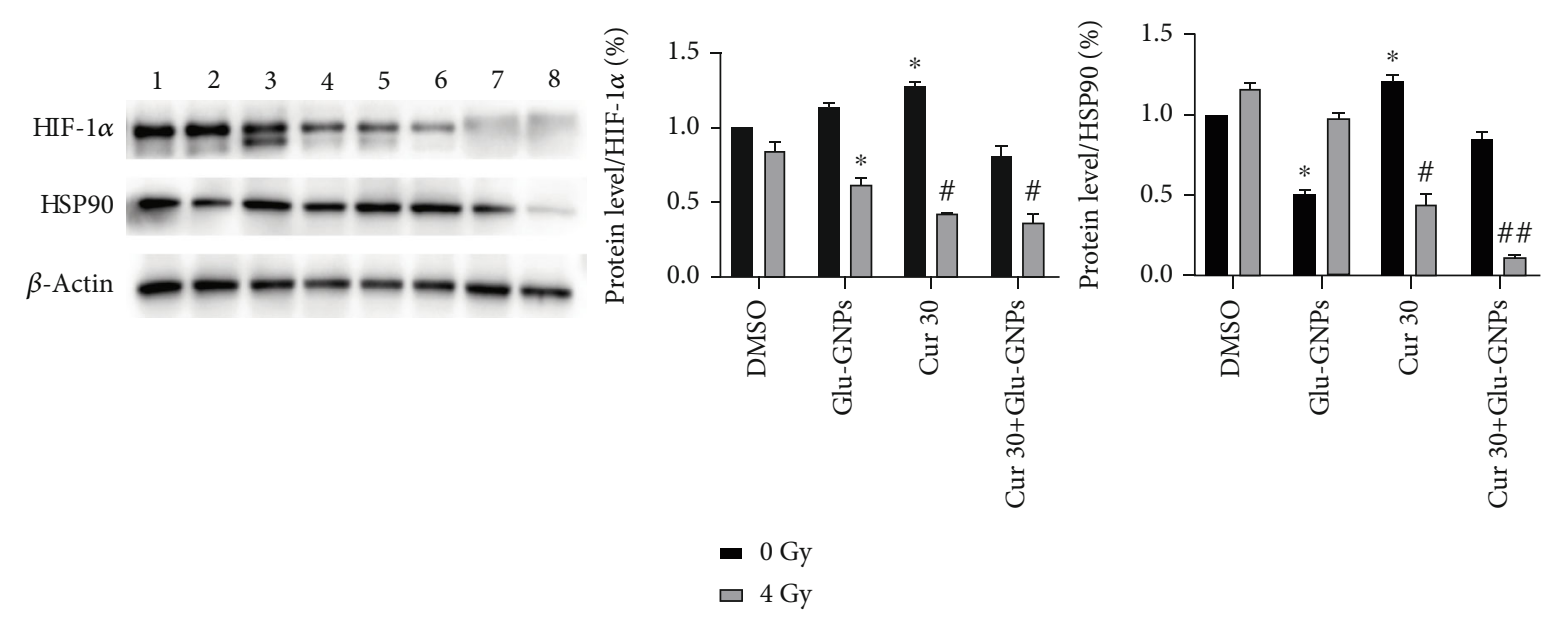

(a)
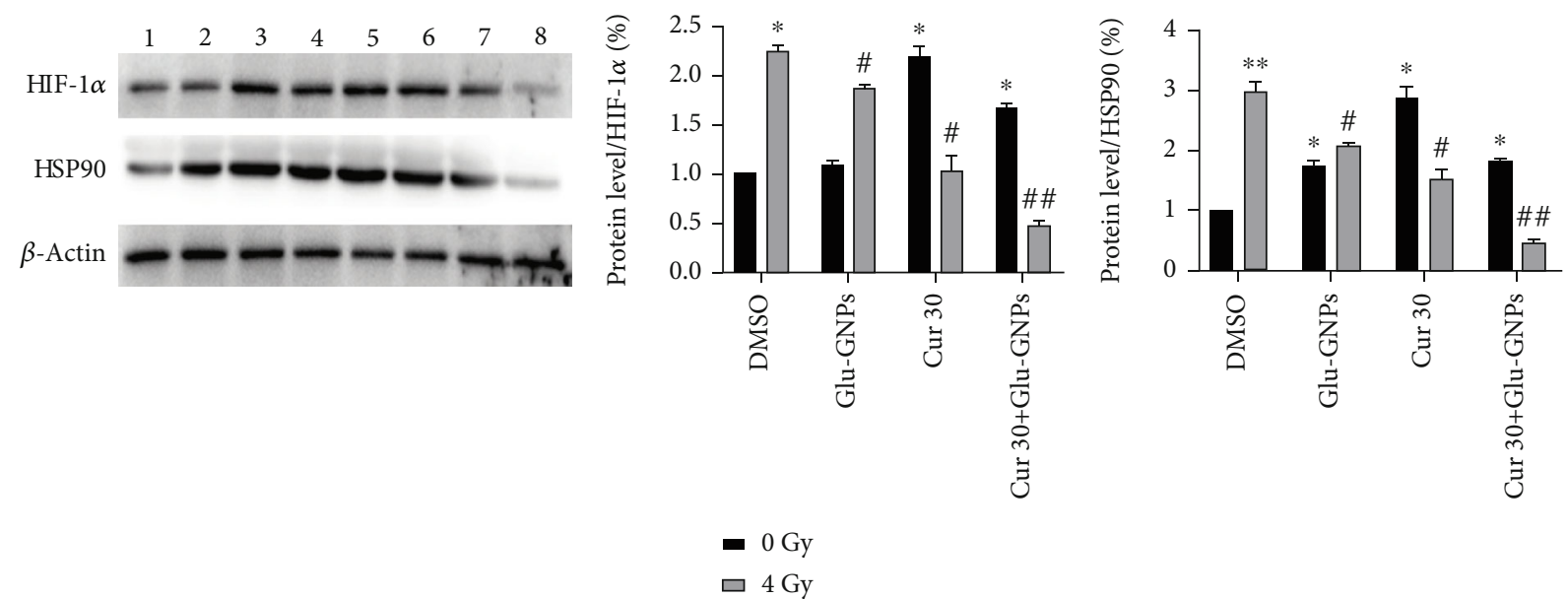

(b)

Figure 6: HIF-1 $\alpha$ and HSP90 protein levels were regulated by curcumin and Glu-GNPs with radiotherapy in two types of spheres. (a) MCF-7 MS and (b) MDA-MB-231 MS treated with 0 or 4 Gy; 1, 2, 3, and 4 (5, 6, 7, and 8) represent, respectively, DMSO, Glu-GNPs, Cur 30, and Cur 30 combined with Glu-GNPs irradiated with 0 (or 4 ) Gy. The data were expressed as a ratio of density of individual proteins to the expression of $\beta$-actin.

malignant tumors, and antioxidant agents can repress the cancerogenesis and metastasis through scavenging ROS. However, on the other hand, some studies showed that the hypoxic region in solid tumors with the decrease of the ROS level lacked oxygen free radicals to damage DNA, leading to radiation resistance of cancer cells and reducing the radiotherapy efficacy.

We continued to investigate if curcumin or Glu-GNPs can affect the ROS level to induce apoptosis and cell cycle changes in BCSCs under hypoxic conditions. Firstly, we used $\mathrm{CoCl}_{2}$ to treat spheres to make a hypoxic cell model. Then, under hypoxic conditions, cell cycle distribution, apoptosis rates, and ROS concentration in each group were detected by FCM. We found that $4 \mathrm{~Gy}$ irradiation alone enhanced the quantity of G0/G1 phase cells and apoptosis rates in two types of spheres. Meanwhile, ROS levels increased significantly after curcumin and Glu-GNP treatment. Under 4 Gy radiation, exposure of tumor spheres to the combination group of curcumin and Glu-GNPs led to significant increase in the ROS level, apoptosis induction, and G0/G1 phase cells.
Furthermore, recent research showed both endogenous and exogenous ROS can mediate DNA damage, multiple apoptotic pathways, and cell cycle arrest to inhibit cancer cells [2830]. Therefore, we propose that the different effects of ROS on tumor development may be related to the tumor staging and radiation, which is worthy of further study.

Based on that, we further explore the underlying mechanism of their radiosensitizing effect in two types of spheres. HIF- $1 \alpha$, as an oxygen-sensitive transcriptional activator, plays a crucial role in tumor survival, progression, and metastasis in hypoxic conditions [31]. The hypoxic microenvironment also provides the basis to cancer stem cells which are involved in cancer metastasis and resistance to therapy [32, 33]. The increase of the HIF- $1 \alpha$ expression can also lead to the reduction of the radiotherapy effect. D. Pagoulatos et al. $[34,35]$ demonstrated that the activity of HSP90 can affect the expression level of HIF-1 $\alpha$, thereby regulating the apoptosis of tumor cells. The expression level of the HSP90 protein may be used as an index of radiosensitivity. In the study, the spheres with hypoxic treatment irradiated by 4 Gy X-ray 
alone led an increase in HIF- $1 \alpha$ and HSP90 mRNA and protein levels. Curcumin and Glu-GNPs lowered the level of both HIF- $1 \alpha$ and HSP90. Furthermore, curcumin acts synergistically with Glu-GNPs to exert more prominent effects. The results suggest that the combination of curcumin and Glu-GNPs have great potential to relieve tumor hypoxia and increase the radiosensitivity on breast cancer stem-like cells.

\section{Conclusions}

Curcumin combined with Glu-GNPs can significantly enhance the radiosensitivity of human breast cancer MCF-7 and MDA-MB-231 mammospheres. Its molecular mechanism may be related to inhibiting the expression of HIF-1a and HSP90, increasing the ROS level and inducing apoptosis of cancer cells.

\section{Abbreviations}

ATCC: American Type Culture Collection

BCSCs: Breast cancer stem-like cells

bFGF: Basic fibroblast growth factor

CCK-8: Cell counting kit-8

DMEM: Dulbecco's modified Eagle's medium

DMSO: Dimethyl sulfoxide

EGF: $\quad$ Epidermal growth factor

EMT: $\quad$ Epithelial-mesenchymal transition

FBS: $\quad$ Fetal bovine serum

FCM: $\quad$ Flow cytometry

FDA: $\quad$ Food and Drug Administration

Glu: $\quad$ 1-Thio-d-glucose

Glu-GNPs: Gold nanoparticles with glucose

GNPs: Gold nanoparticles

MS: $\quad$ Mammospheres

PBS: $\quad$ Phosphate-buffered saline

PEG: $\quad$ Polyethylene glycol

ROS: $\quad$ Reactive oxygen species

SF: $\quad$ Survival fraction

SFM: $\quad$ Serum-free medium

TBS: $\quad$ Tris-HCl-buffered saline

TEM: Transmission electron microscopy.

\section{Data Availability}

The data used to support the findings of this study are included within this article.

\section{Conflicts of Interest}

We wish to confirm that there are no known conflicts of interest associated with this publication, and there has been no significant financial support for this work that could have influenced its outcome.

\section{Authors' Contributions}

Chenxia $\mathrm{Hu}$ conceived and designed the study. Ke Yang, Yujian Wu, Mengje Li, Jiayi Lin, and Tingting Guo carried out the experiments. Zhiwei Liao and Yanwu Li provided the equipment for radiotherapy and technical guidance for the research. Ke Yang analyzed the data. Ke Yang and Chenxia $\mathrm{Hu}$ drafted and modified the manuscript. All authors read and approved the final manuscript.

\section{Acknowledgments}

The authors thank the staff at Radiotherapy Center in Guangzhou Medical University Affiliated Cancer Hospital for providing irradiation on cancer cells in the experiments. This study was supported by grants from the National Natural Science Foundation of China (Nos. 81503301 and 81873052).

\section{References}

[1] R. L. Siegel, K. D. Miller, and A. Jemal, "Cancer statistics, 2019," CA: a Cancer Journal for Clinicians, vol. 69, no. 1, pp. 7-34, 2018.

[2] M. Al-Hajj, M. S. Wicha, A. Benito-Hernandez, S. J. Morrison, and M. F. Clarke, "Prospective identification of tumorigenic breast cancer cells," Proceedings of the National of Acadamy of Sciences of the United States of America, vol. 100, no. 7, pp. 3983-3988, 2003.

[3] C. Lagadec, C. Dekmezian, L. Bauche, and F. Pajonk, "Oxygen levels do not determine radiation survival of breast cancer stem cells," PLoS One, vol. 7, no. 3, article e34545, 2012.

[4] C. Lagadec, E. Vlashi, L. D. Donna et al., "Survival and selfrenewing capacity of breast cancer initiating cells during fractionated radiation treatment," Breast Cancer Research, vol. 12, no. 1, p. R13, 2010.

[5] W. Chen, Y. Qin, and S. Liu, "Cytokines. Breast cancer stem cells (BCSCs) and chemoresistance," Clinical and Translational Medicine, vol. 7, no. 1, p. 27, 2018.

[6] M. P. Moreira, L. da Conceição Braga, G. D. Cassali, and L. M. Silva, “_STAT3_ as a promising chemoresistance biomarker associated with the $\mathrm{CD} 44^{+/ \text {high }} / \mathrm{CD} 24^{-/ \text {low }} / \mathrm{ALDH}^{+}$BCSCslike subset of the triple-negative breast cancer (TNBC) cell line," Experimental Cell Research, vol. 363, no. 2, pp. 283290, 2018.

[7] T. M. Phillips, W. H. McBride, and F. Pajonk, "The response of $\mathrm{CD} 24^{- \text {low }} / \mathrm{CD} 44^{+}$breast cancer-initiating cells to radiation," JNCI: Journal of the National Cancer Institute, vol. 98, no. 24, pp. 1777-1785, 2006.

[8] L. R. Hirsch, R. J. Stafford, J. A. Bankson et al., "Nanoshellmediated near-infrared thermal therapy of tumors under magnetic resonance guidance," Proceedings of the National Academy of Sciences, vol. 100, no. 23, pp. 13549-13554, 2011.

[9] L. I. Xiao-Hong, H. U. Li-Kuan, C. H. Wang, and D. U. Yuan$\mathrm{Na}$, "Radiosensitivity enhancement of the human lung adenocarcinoma cell line A549 by Glu-GNPs," Journal of Shandong University, vol. 50, no. 3, 2012.

[10] T. Kong, J. Zeng, X. Wang et al., "Enhancement of radiation cytotoxicity in breast-cancer cells by localized attachment of gold nanoparticles,” Small, vol. 4, no. 9, pp. 1537-1543, 2010.

[11] W. Roa, X. Zhang, S. Patel et al., "Gold-nanoparticles sensitize radiotherapy of prostate cancer cells by regulation of cell cycle," Radiotherapy and Oncology, vol. 92, no. 12, p. S16, 2009.

[12] C. Hu, M. Niestroj, D. Yuan, S. Chang, and J. Chen, “Treating cancer stem cells and cancer metastasis using glucose-coated 
gold nanoparticles," International Journal of Nanomedicine, vol. 10, pp. 2065-2077, 2015.

[13] C. Loo, A. Lowery, N. Halas, J. West, and R. Drezek, "Immunotargeted nanoshells for integrated cancer imaging and therapy," Nano Letters, vol. 5, no. 4, pp. 709-711, 2005.

[14] H. N. McQuaid, M. F. Muir, L. E. Taggart et al., "Imaging and radiation effects of gold nanoparticles in tumour cells," Scientific Reports, vol. 6, 2016.

[15] A. Shehzad, J. W. Park, J. Lee, and Y. S. Lee, "Curcumin induces radiosensitivity of in vitro and in vivo cancer models by modulating pre-mRNA processing factor 4 (Prp4)," Chemico-Biological Interactions, vol. 206, no. 2, pp. 394-402, 2013.

[16] L. Huang, M. Cai, X. Xie, Y. Chen, and X. Luo, "Uptake enhancement of curcumin encapsulated into phosphatidylcholineshielding micelles by cancer cells," Journal of Biomaterials Science. Polymer Edition, vol. 25, no. 13, pp. 1407-1424, 2014.

[17] P. Basnet and N. Skalko-Basnet, "Curcumin: an antiinflammatory molecule from a curry spice on the path to cancer treatment," Molecules, vol. 16, no. 6, pp. 4567-4598, 2011.

[18] C. Hu, M. Li, T. Guo et al., "Anti-metastasis activity of curcumin against breast cancer via the inhibition of stem cell-like properties and EMT," Phytomedicine, vol. 58, no. 5, p. 152740, 2019.

[19] G. Dontu and M. S. Wicha, "Survival of mammary stem cells in suspension culture: implications for stem cell biology and neoplasia," Journal of Mammary Gland Biology and Neoplasia, vol. 10, no. 1, pp. 75-86, 2005.

[20] D. Ponti, A. Costa, N. Zaffaroni et al., "Isolation and in vitro propagation of tumorigenic breast cancer cells with stem/progenitor cell properties," Cancer Research, vol. 65, no. 13, pp. 5506-5511, 2005.

[21] A. B. Kunnumakkara, D. Bordoloi, G. Padmavathi et al., "Curcumin, the golden nutraceutical: multitargeting for multiple chronic diseases," British Journal of Pharmacology, vol. 174, no. 11, pp. 1325-1348, 2017.

[22] X.-P. Wang, Q.-X. Wang, H.-P. Lin, and N. Chang, “Antitumor bioactivities of curcumin on mice loaded with gastric carcinoma," Food \& Function, vol. 8, no. 9, pp. 3319-3326, 2017.

[23] J. W. Zhan, D. M. Jiao, Y. Wang et al., "Integrated microRNA and gene expression profiling reveals the crucial miRNAs in curcumin anti-lung cancer cell invasion," Thoracic Cancer, vol. 8, no. 5, pp. 461-470, 2017.

[24] F. Liao, L. Liu, E. Luo, and J. Hu, "Curcumin enhances antitumor immune response in tongue squamous cell carcinoma," Archives of Oral Biology, vol. 92, pp. 32-37, 2018.

[25] B. Farhood, K. Mortezaee, N.-H. Goradel et al., "Curcumin as an anti-inflammatory agent: implications to radiotherapy and chemotherapy," Journal of Cellular Physiology, vol. 234, no. 5, pp. 5728-5740, 2019.

[26] L. Minafra, N. Porcino, V. Bravatà et al., "Radiosensitizing effect of curcumin-loaded lipid nanoparticles in breast cancer cells," Scientific Reports, vol. 9, no. 1, p. 11134, 2019.

[27] V. Verma, "Relationship and interactions of curcumin with radiation therapy," World Journal of Clinical Oncology, vol. 7, no. 3, pp. 275-283, 2016.

[28] V. Rincheval, M. Bergeaud, L. Mathieu et al., "Differential effects of Bcl-2 and caspases on mitochondrial permeabilization during endogenous or exogenous reactive oxygen species-induced cell death," Cell Biology and Toxicology, vol. 28, no. 4, pp. 239-253, 2012.
[29] S.-Y. Zhang, X.-B. Li, S.-G. Hou, Y. Sun, Y.-R. Shi, and S.S. Lin, "Cedrol induces autophagy and apoptotic cell death in A549 non-small cell lung carcinoma cells through the P13K/Akt signaling pathway, the loss of mitochondrial transmembrane potential and the generation of ROS," International Journal of Molecular Medicine, vol. 38, no. 1, pp. 291-299, 2016.

[30] F. Salehi, H. Behboudi, G. Kavoosi, and S. K. Ardestani, "Chitosan promotes ROS-mediated apoptosis and S phase cell cycle arrest in triple-negative breast cancer cells: evidence for intercalative interaction with genomic DNA," RSC Advances, vol. 7, no. 68, pp. 43141-43150, 2017.

[31] K. Nakayama, "Cellular signal transduction of the hypoxia response," Journal of Biochemistry, vol. 146, no. 6, pp. 757$765,2009$.

[32] C.-P. Cui, C. C.-L. Wong, A. K.-L. Kai et al., "SENP1 promotes hypoxia-induced cancer stemness by HIF- $1 \alpha$ deSUMOylation and SENP1/HIF- $1 \alpha$ positive feedback loop," Gut, vol. 66, no. 12, pp. 2149-2159, 2017.

[33] H. Kim, Q. Lin, P. M. Glazer, and Z. Yun, “The hypoxic tumor microenvironment in vivo selects the cancer stem cell fate of breast cancer cells," Breast Cancer Research, vol. 20, no. 1, p. 16, 2018.

[34] S. Zhao, D. T. Dicker, and W. S. El-Deiry, "Dual inhibition of CDK1 and HSP90 destabilizes HIF1 $\alpha$ and synergistically induces cancer cell death," Cancer Research, vol. 77, p. 4516, 2017.

[35] D. Pagoulatos, N. Pharmakakis, J. Lakoumentas, and M. Assimakopoulou, "Hypoxia-inducible factor- $1 \alpha$, von Hippel-Lindau protein, and heat shock protein expression in ophthalmic pterygium and normal conjunctiva," Molecular Vision, vol. 20, pp. 441-457, 2014. 